\title{
Influence of Montmorillonite K10 Modification with Tungstophosphoric Acid on Hybrid Catalyst Activity in Direct Dimethyl Ether Synthesis from Syngas
}

\author{
M. Śliwa • K. Samson • M. Ruggiero-Mikołajczyk • \\ A. Żelazny $\cdot$ R. Grabowski
}

Received: 11 June 2014/ Accepted: 1 September 2014/Published online: 16 September 2014

(C) The Author(s) 2014. This article is published with open access at Springerlink.com

\begin{abstract}
Dimethyl ether synthesis was performed from syngas over hybrid catalysts comprising a $\mathrm{Cu} / \mathrm{Zn} / \mathrm{Al}$ as metallic function and K10-montorillonite (K10) as acidic function. The acidic properties of K10 were tuned by deposition of one monolayer of tungstophosphoric acid $\left(\mathrm{H}_{3} \mathrm{PW}_{12}\right.$ $\mathrm{O}_{40} \cdot 23.5 \mathrm{H}_{2} \mathrm{O}$, TPA). The changes in acidity were determined based on pyridine adsorption with FTIR detection. Due to the fact that TPA does not possess Lewis acid sites, deposition of TPA on the K10 surface (TPA-K10) resulted only in increase in Brønsted acid site concentrations and in increase in their strength in comparison with unmodified K10. Since both modified and unmodified K10 exhibited the same Lewis acid site concentrations and their strength, it was possible to investigate solely the impact of Brønsted acidity differences of acidic functions on the hybrid catalysts activity in syngas-toDME process (STD). Additionally, the effect of TPA supported on K10 was investigated in methanol dehydration to DME under atmospheric pressure. In order to prepare metallic functions which differed in activity in $\mathrm{CO}$ hydrogenation to methanol (first step of STD), two synthesis methods were used: co-precipitation method (metallic function CZA) and decomposition of citrate complexes of metals (metallic function $\left.\mathrm{CZA}_{\text {citric }}\right)$. The hybrid catalysts $(\mathrm{CZA} / \mathrm{K} 10, \mathrm{CZA} /$ TPA-K10, CZA citric $_{\text {K10, }} \mathrm{CZA}_{\text {citric }} / \mathrm{TPA}-\mathrm{K} 10$ ) for STD were prepared by physical mixing of metallic and acidic function in volume ratio equal to $2: 1$. The impact of $\mathrm{K} 10$ substitution with TPA-10 in hybrid catalysts depended on whether STD process was controlled by methanol synthesis step or dehydration
\end{abstract}

M. Śliwa ( $\square) \cdot$ K. Samson · M. Ruggiero-Mikołajczyk ·

A. Żelazny · R. Grabowski

Jerzy Haber Institute of Catalysis and Surface Chemistry Polish

Academy of Sciences, Niezapominajek 8, 30 - 239 Cracow, Poland

e-mail: ncsliwa@cyf-kr.edu.pl methanol step. When K10 possessed adequate acidity to dehydrate methanol formed on metallic function (i.e. CZA $_{\text {citric }}$ ), it substitution with TPA-K10 in hybrid catalyst did not improve DME yield. On the other hand, when metallic function (i.e. CZA) exhibited higher methanol activity and methanol dehydration rate was limited by insufficient acidity of K10 then usage of TPA-K10 of higher acidity in hybrid catalyst was found to increase significantly DME yield without light parrafins formation.

Keywords Dimethyl ether synthesis - Hybrid catalyst . $\mathrm{K} 10$-montmorillonite $\cdot$ Acidity $\cdot \mathrm{Cu} / \mathrm{Zn} / \mathrm{Al}$.

Tungstophosphoric acid

\section{Introduction}

The diminishing world resources of crude oil and its unstable market prices together with aggravated requirements concerning pollutant emission levels for combustion engines are one of the reasons for seeking a new technology of obtaining clean fuels from renewable energy sources. One of such promising benign fuel, which has recently attracted more attention, is DME. The main advantage of DME is the diversification of feedstocks, which it can be synthesized from (e.g. biomass, natural gas, coal). Because of physicochemical properties (i.e. high cetane number, low boiling point, high oxygen content), DME is suitable for using as a clean fuel in compressed engines [1, 2]. Additionally, there is variety of the interesting purposes for which DME can be applied. There are papers regarding usage of DME in fuel cells for hydrogen generation [3, 4]. DME is also of great importance from the industrial point of view since it is crucial intermediate for the synthesis of dimethyl sulfate, methyl acetate, and light olefins $[5,6]$. 
It is commonly known that there are two possible chemical routes for synthesis of DME. One, in which two separates reactions occur, is called indirect synthesis of DME. During the first step, methanol is synthesized either from synthesis gas or from a mixture of $\mathrm{H}_{2} / \mathrm{CO}_{2}$ and in the next step it is dehydrated to DME. Since the beginning of the 1990's a new process, called syngas-to-DME (STD), has been developed. In this case, DME is synthesized in one-step via methanol as intermediate. The main advantage of the STD process over conventional two-step DME synthesis is that it is more thermodynamically favorable. Thus, during the STD process the yields of DME are improved and syngas conversions are higher. For that reason, the production cost of DME in STD process is lower than in traditional DME synthesis [7].

The main reactions taking place in STD process are: hydrogenation of CO (1), dehydration of methanol (2), water gas shift reaction (3).

$$
2 \mathrm{CO}+4 \mathrm{H}_{2}=2 \mathrm{CH}_{3} \mathrm{OH} \quad \Delta \mathrm{H}=-180.58 \mathrm{~kJ} / \mathrm{mol}
$$

$2 \mathrm{CH}_{3} \mathrm{OH}=\mathrm{CH}_{3} \mathrm{OCH}_{3}+\mathrm{H}_{2} \mathrm{O}$

$\Delta \mathrm{H}=-23.41 \mathrm{~kJ} / \mathrm{mol}$

$\mathrm{H}_{2} \mathrm{O}+\mathrm{CO}=\mathrm{H}_{2}+\mathrm{CO}_{2} \quad \Delta \mathrm{H}=-40.96 \mathrm{~kJ} / \mathrm{mol}$

The net reaction of STD process is exothermic and is given by the following equation:

$$
\begin{gathered}
3 \mathrm{H}_{2}+3 \mathrm{CO}=\mathrm{CH}_{3} \mathrm{OCH}_{3}+\mathrm{CO}_{2} \\
\Delta \mathrm{H}=-244.95 \mathrm{~kJ} / \mathrm{mol}
\end{gathered}
$$

The STD process requires the special hybrid catalyst application, which has both redox centers and acidic centers. The redox centers are responsible for hydrogenation of $\mathrm{CO}_{\mathrm{x}}$ to methanol while acidic ones are active sites in subsequent methanol dehydration to DME. Copper based catalysts are used as metallic components of hybrid catalysts. Both binary $(\mathrm{Cu} / \mathrm{Zn})[8]$ and ternary $(\mathrm{Cu} / \mathrm{Zn} / \mathrm{Al}, \mathrm{Cu}$ / $\mathrm{Zn} / \mathrm{Zr}$ ) [9, 10] methanol catalysts are successfully applied. These metallic function are often modified by promoters addition e.g.: $\mathrm{Mn}$, Ga [11, 12]. The structural-activity relationship for metallic component in STD process is established. Moreover, influence of promoter additions on physicochemical properties of $\mathrm{Cu}$-based components of hybrid catalysts and on their activity in STD process is well known and explained [13-15]. Thus, considerably focus is being paid to the role of the acidic function in methanol dehydration step. The most extensively studied acidic function are $\gamma$-Al2O3 [12, 16], HZSM-5 [17, 18] and HY [19]. The use of HZSM-5, characterized by high strength of acid sites, leads to higher selectivity to by-products (i.e.: hydrocarbons) [20]. Therefore, acidic properties of ZSM-5 are often tuned, by ion-exchange which results in increase in DME selectivity and decrease in selectivity to C1-C5 hydrocarbons and to $\mathrm{CO} 2$ [21-23]. On the other hand, hydrophilicity of $\gamma-\mathrm{Al} 2 \mathrm{O} 3$ causes that water, which is formed during STD process, can easily adsorb on Lewis acid sites of $\gamma$-Al2O3 leading to quick deactivation of the catalysts [24, 25]. There are also reports concerning usage of different SAPO materials [26] and HMCM-22 [27] as acidic components of hybrid catalysts.

In the scientific literature there is an ongoing debate on whether weak/moderate acid centers or strong acid centers play crucial role in methanol dehydration step to DME in STD process. Kim et al. [28]. states that strong acid sites are responsible for methanol dehydration to DME, while acid centers characterized by desorption bands below $450{ }^{\circ} \mathrm{C}$ in $\mathrm{NH} 3$ - TPD measurements do not play role in STD process. In the contrary to this are results of $\mathrm{Xu}$ et al. [29]. and Joo et al. [30]. showing that strong acid sites favor the formation of hydrocarbons and $\mathrm{CO} 2$ and weak/ moderate acid site are needed for high DME selectivity. The studies of Ramos et al. [31]. reveals that correlation between acidity strength and activity of hybrid catalysts in STD process is not straightforward. Surprisingly, ZSM-5 and $\mathrm{S}-\mathrm{ZrO}_{2}$ (sulfated zirconia) which differ significantly in activity in methanol dehydration reaction to DME, after being mixed with commercial methanol catalysts $(\mathrm{Cu} / \mathrm{Zn} /$ Al) exhibit similar activity in STD process. On the other hand, the activity of hybrid catalysts composing of $\mathrm{Cu} / \mathrm{Zn} /$ $\mathrm{Al}$ and $\mathrm{Al}_{2} \mathrm{O}_{3}$ or $\mathrm{W} / \mathrm{ZrO}_{2}$ in STD process correlate with activity of $\mathrm{Al}_{2} \mathrm{O}_{3}$ and $\mathrm{W} / \mathrm{ZrO}_{2}$ in methanol dehydration to DME. Based on that, authors conclude that in first case STD process can be limited by methanol synthesis step whereas in second case by methanol dehydration step.

In order to investigate STD process under condition when it is limited by methanol synthesis rate or methanol dehydration rate, we synthesized first metallic functions of different activities in methanol synthesis. It is well know from the literature [32] that BET surface area, copper surface area and copper dispersion are one of the factors which have impact on the activity of copper based catalysts in the methanol synthesis from syngas. The application of carbonate and citric method allowed to obtained metallic function which differed significantly in above-mentioned properties and therefore varied in activity in methanol synthesis step.

Recently, clay based-materials such as K10-montmorillonite has attracted more attention since they are considered as environmentally friendly and recyclable catalysts [33], [34].The commercially available K10montmorillonite is a smectite clay activated by inorganic acid. The acid treatment increases BET surface area (change pore size distribution of montmorillonite) and results in an acidity strengthening hybrid catalysts. 
Although both K10-montmorillonite and heteropoly acids (HPAs) are used as heterogeneous catalysts, according to our knowledge, no information can be found regarding usage of pure K10-montmorillonite or HPAs supported on K10-montmorillonite as hybrid catalyst for STD process. Thus, in the presented studies, we report for the first time, the usage of K10-montmorillonite as acidic function of hybrid catalyst for syngas-to-DME process. Additionally, the influence of K10 modification with tungstophosphoric acid (TPA) on its physicochemical properties (e.i.: acidity, porosity) and on activity in STD process has been studied.

\section{Experimental}

\subsection{Catalysts Preparation}

The $\mathrm{Cu} / \mathrm{Zn} / \mathrm{Al}$ metallic function was obtained by co-precipitation method (referred as the carbonate method) and by decomposition of citrate complexes of metals (referred as the citric method) The nominal composition of synthesized metallic functions was: $66 \mathrm{wt} \% \mathrm{CuO}, 23 \mathrm{wt} \% \mathrm{ZnO}$ and $9 \mathrm{wt} \% \mathrm{Al}_{2} \mathrm{O}_{3}$.

In the case of carbonate method, the synthesis of metallic function was performed at $\mathrm{pH}=7 . \mathrm{Na}_{2} \mathrm{CO}_{3}$ as precipitating agent and solution of cations in forms of nitrates were added simultaneously into demineralized water at $60{ }^{\circ} \mathrm{C}$, under vigorous stirring. Afterwards, the precipitates of mixed basic carbonates were washed by five times centrifugation at the $3,500 \mathrm{rpm}$, dried at $100{ }^{\circ} \mathrm{C}$ and calcined in air for $3 \mathrm{~h}$ at $350{ }^{\circ} \mathrm{C}$. The obtained metallic function by carbonate method is designated as CZA.

For the citric method, the solutions of appropriate cations in forms of nitrates and citric acid were added at once. The obtained solution was evaporated in rotary evaporator under vacuum. Afterwards, the precipitates of the citrate complexes of metals were washed by five times centrifugation at the $3,500 \mathrm{rpm}$, dried at $100{ }^{\circ} \mathrm{C}$ and calcined in air for $3 \mathrm{~h}$ at $350{ }^{\circ} \mathrm{C}$. The obtained metallic function by citric method is designated as $\mathrm{CZA}_{\text {citric }}$. The Aldrich reagents used for the synthesis were of $99.99 \%$ purity.

The commercial K10-montmorillonite (K10) was used as an acidic component of hybrid catalyst. The modification of K10 by one monolayer deposition of TPA was carried out by incipient wetness impregnation method. The appropriate amount of TPA (needed for one monolayer coverage) was calculated based on BET surface area of montmorillonite $\mathrm{K} 10$ and with the assumption that one Keggin unit occupies the surface of $144 \AA^{2}$. Prior to the modification, K10 was dried at $120{ }^{\circ} \mathrm{C}$ for $12 \mathrm{~h}$. Next, a water solution containing a suitable amount of TPA was added to K10. The obtained slurry was mixed and dried at
$90{ }^{\circ} \mathrm{C}$ for $12 \mathrm{~h}$. The prepared acidic function is designated as TPA-K10.

The hybrid catalysts were obtained by physical mixing of metallic function and the acidic function (grain size $0.64-1 \mathrm{~mm}$ ) with the volume ratio equal to $2: 1$.

\subsection{Catalysts Characterization}

The phase composition of fresh metallic and acidic functions was determined by X-ray powder diffraction (XRD). The analysis was performed between 20 and $1102 \Theta$ range using a Bruker AXS D505 powder diffractometer with $\mathrm{CuK} \alpha$ radiation. The crystallites sizes of $\mathrm{CuO}$ in fresh metallic functions were estimated by multiphase Rietveld refinement method using TOPAS software.

Thermo-programmed reduction $\left(\mathrm{H}_{2}-\mathrm{TPR}\right)$ was conducted in order to examine the reducibility of the metallic components. The reduction measurements were carried out on Chembet-3000. About $0.01 \mathrm{~g}$ of each metallic catalyst was diluted with ca. $0.25 \mathrm{~g}$ of $\mathrm{Al}_{2} \mathrm{O}_{3}$ and $0.1 \mathrm{~g}$ of such mixture was placed in the u-shape quartz flow reactor. The mixture of $5 \% \mathrm{H}_{2} / \mathrm{Ar}$ was used as reducing agent. TPR profiles were recorded with TCD detector. During the reduction, the flow of the reducing agent was kept constant at $30 \mathrm{~mL} / \mathrm{min}$ and the temperature was elevated with a ramp of $10 \mathrm{deg} / \mathrm{min}$, in the $20-650{ }^{\circ} \mathrm{C}$ range. The water formed during reduction was removed from the flow in a cold trap. The copper dispersion $\left(\mathrm{D}_{\mathrm{Cu}}\right)$ was determined based on the hydrogen consumption in the TPR measurements (bulk and surface copper reduction, A) and the hydrogen consumption in the measurements of $\mathrm{N}_{2} \mathrm{O}$ decomposition (surface copper reduction only, $\mathrm{B}$ ). According to assumptions made by E.D. Guerreiro et al [35]., the following expression can be used for copper dispersion calculation: $\mathrm{D}=2 \times \mathrm{A} / \mathrm{B}$.

The specific surface area and the pore size distribution were measured by N2 adsorption on a Quantachrome Autosorb-1. Before the experiment, the samples were degassed at $100{ }^{\circ} \mathrm{C} \mathrm{K}$ for $18 \mathrm{~h}$ under vacuum (ca. $10^{-6} \mathrm{Tr}$ ) and then the $\mathrm{N} 2$ adsorption was performed at $-195.7^{\circ} \mathrm{C}$.

The copper surface area in the reduced catalysts was determined by reactive adsorption of $\mathrm{N} 2 \mathrm{O}$ at $90{ }^{\circ} \mathrm{C}$ according to the method described somewhere else [36]. The measurements were carried out in a quartz flow microreactor. Around $0.25 \mathrm{~g}$ of catalyst was loaded into the reactor and the sample was reduced for $2 \mathrm{~h}$ at $250{ }^{\circ} \mathrm{C}$ in the flow of $5 \% \mathrm{H}_{2} / \mathrm{Ar}$. Afterwards, the reactor was cooled down to $90{ }^{\circ} \mathrm{C}$. Then $100 \mu \mathrm{l}$ of $\mathrm{N}_{2} \mathrm{O}$ pulses were injected until the reaction was completed. Amount of the reacted of $\mathrm{N}_{2} \mathrm{O}$ was determined using a mass spectrometer (VG/Fisions Quartz 200 D). It was assumed in calculations that the reoxidation of the surface copper follows the equation: 
$2 \mathrm{Cu}_{(\mathrm{s})}+\mathrm{N}_{2} \mathrm{O}_{(\mathrm{g})}=\mathrm{Cu}_{2} \mathrm{O}_{(\mathrm{s})}+\mathrm{N}_{2}$

and $1 \mathrm{~m}^{2}$ of elemental copper corresponds to $6.1 \mu \mathrm{mol} \mathrm{O}_{2}$.

Chemical analysis was performed by inductively coupled-plasma optical emission spectroscopy (ICP-OES).

The acidic properties of the acidic functions were determined based on pyridine adsorption with FTIR detection. The spectra were collected with a Bruker Equinox $55 \mathrm{spec}-$ trometer (equipped with an MCT detector) with the spectral resolution of $2 \mathrm{~cm}^{-1}$. For the FTIR measurements, the acidic samples were pressed into wafers and activated and prereduced in situ in an IR cell in vacuum $\left(7.5 \times 10^{-5} \mathrm{Tr}\right)$ at 250 or $350{ }^{\circ} \mathrm{C}$ for $40 \mathrm{~min}$. The pyridine was desorbed at $150{ }^{\circ} \mathrm{C}$ and $350{ }^{\circ} \mathrm{C}$. The acidic strength was determined, according to [37] and [38], based on the ratio $I_{350} / I_{150}$ where $I_{350}$ is the intensity of the pyridine bands after desorption at $350{ }^{\circ} \mathrm{C}$ and $\mathrm{I}_{150}$ is the intensity of the pyridine bands after desorption at $150{ }^{\circ} \mathrm{C}$ for the samples activated at $250{ }^{\circ} \mathrm{C}$. In order to calculate the concentration of Brønsted and Lewis sites, the following bands and adsorption coefficients were employed: pyridine $\mathrm{PyH}^{+}$band at $1,540 \mathrm{~cm}^{-1}, \varepsilon=0.078 \mathrm{~cm} / \mu \mathrm{mol}$, pyridine PyL band at $1,454 \mathrm{~cm}^{-1}, \varepsilon=0.165 \mathrm{~cm} / \mu \mathrm{mol}$ [39].

The UV-Vis measurements were performed using a Perkin-Elmer Lambda 35 spectrometer in the wavelength range $200-1,100 \mathrm{~nm}$. The samples of the acidic functions were dissolved in acetonitrile (ACN). A solution of pure ACN was used as a reference sample. The amount of TPA deposited during impregnation was determined based on external standard calibration. For this purpose, the series of TPA solutions in ACN, of appropriate concentrations, were prepared. Then, the signal at $256 \mathrm{~nm}$ was integrated and used for the TPA quantification. The prepared calibration solutions and investigated samples were $1.5 \mathrm{~mL}$.

The methanol (MeOH) dehydration to DME was carried out in the fixed-bed flow reactor at atmospheric pressure. Typically, $0.6 \mathrm{~cm}^{3}$ of CZA and $\mathrm{CZA}_{\text {citric }}$ was placed in the reactor and the $\mathrm{MeOH}$ vapor was introduced. The substrates and products of the reaction were analyzed online by gas chromatograph equipped in TCD detector.

\subsection{Catalytic Activity Measurements}

The activity of hybrid catalysts in STD process was tested in a high pressure stainless steel fixed-bed flow reactor (vol. ca $8 \mathrm{~cm}^{3}$ ) connected online to gas chromatograph, equipped with a TCD detector for $\mathrm{H}_{2}, \mathrm{CO}, \mathrm{CO}_{2}$ and a FID detector for organic compounds analysis. The metallic and acidic functions were pressed into tablets and sieved (grain size 0.64-1 mm). Next, metallic and acidic functions were physically mixed with volume ratio $2: 1$. The $1 \mathrm{~cm}^{3}$ volume of hybrid catalyst, without being diluted in an inert material, was placed in the reactor. The thermocouple was put inside the catalyst bed to monitor precisely reaction temperature. Before the catalytic experiments, the hybrid catalysts were reduced in a stream of $5 \% \mathrm{H}_{2} / \mathrm{N}_{2}$ mixture at $200{ }^{\circ} \mathrm{C}$ for $3 \mathrm{~h}$ under atmospheric pressure and subsequently activated in the flow of reactant mixture $\left(5 \% \mathrm{CO}_{2} / 30 \% \mathrm{CO} / \mathrm{rest}_{2}\right)$ at elevated temperatures from 200 to $350{ }^{\circ} \mathrm{C}$ with the ramp of $20 \mathrm{deg}$. Next, the temperature was decreased to $280{ }^{\circ} \mathrm{C}$. The catalytic measurements were carried out in the range $280-360{ }^{\circ} \mathrm{C}$, under the pressure of 40 bars and gas hourly space velocity, GHSV $=3,600 \mathrm{~h}^{-1}$. In order to prevent methanol and water condensation, all lines were heated around $120^{\circ} \mathrm{C}$.

\section{Results and Discussion}

\subsection{Metallic Function Characterization (CZA, $\left.\mathrm{CZA}_{\text {citric }}\right)$}

The main physicochemical properties of $\mathrm{CZA}$ and $\mathrm{CZA}_{\text {citric }}$ are listed in Table 1. The chemical composition of CZA and $\mathrm{CZA}_{\text {citric }}$ determined by ICP-OES are in good agreement with the nominal composition ( $66 \mathrm{wt} \% \mathrm{CuO}, 23 \mathrm{wt} \% \mathrm{ZnO}, 9 \mathrm{wt} \%$ $\mathrm{Al}_{2} \mathrm{O}_{3}$ ). Both synthesized metallic functions differ significantly in their physicochemical properties due to employed method of synthesis. CZA exhibits higher BET surface area and higher $\mathrm{Cu}$ surface area in comparison with metallic function obtained by citric method $\left(\mathrm{CZA}_{\text {citric }}\right)$. The mean particles diameter of $\mathrm{Cu}^{\circ}$ in $\mathrm{CZA}$ and $\mathrm{CZA}_{\text {citric }}$ was determined according to assumptions of spherical particle model [40]. The following equation $d=6,000 /(\rho \times S / C)$, where $S$ is the copper surface area (based on $\mathrm{N}_{2} \mathrm{O}$ decomposition), $\rho$ is the copper density $\left(8.92 \mathrm{~g} / \mathrm{cm}^{3}\right), \mathrm{C}$ is the $\mathrm{Cu}$ content (wt\%) from ICP-OES measurements, was used. The results show that mean particles diameter of $\mathrm{Cu}^{\circ}$ is $12.0 \mathrm{~nm}$ and $29.5 \mathrm{~nm}$, respectively for $\mathrm{CZA}$ and $\mathrm{CZA}_{\text {citric }}$. The XRD patterns of fresh metallic functions, after precursors calcination, are presented in Fig. 1. The $\mathrm{CuO}$ phase (main peaks: $2 \Theta=35.5^{\circ}$ and $39^{\circ}$ ) dominates in the all samples. Apart from the crystalline $\mathrm{CuO}$, in the studied catalysts $\mathrm{CuO}$ can be present in the amorphous phase as well [32]. $\mathrm{ZnO}\left(2 \Theta=32^{\circ}\right)$ is the second crystalline phase which is distinguished. The absence of the characteristic reflections for $\mathrm{Al}_{2} \mathrm{O}_{3}$ can be explained either by it low concentration or by the amorphous state in which this oxide is present in both synthesized metallic functions. In the literature, the formation of solid solution of $\mathrm{CuAl}_{2} \mathrm{O}_{4}$ spinel is observed in the ternary systems. Moreover, the small amounts of $\mathrm{Cu}^{2+}$ might dissolve in the $\mathrm{ZnO}$ lattice $[41,42]$ and the solid solution of $\mathrm{Zn}$ in $\mathrm{CuO}$ can be formed [43]. Nevertheless, Moretti et al. [44]. is in the opposition to this statement. Based on the XPS studies, authors claim that the presence of solid solution of $\mathrm{Cu}$ in $\mathrm{ZnO}$ is not such straightforward. Another option is incorporation of $\mathrm{Al}$ into $\mathrm{ZnO}$ lattice [45]. This can lead to structural and electronic promotion effects affecting catalytic properties of $\mathrm{Cu}$ surface. In the case of the XRD 
Table 1 Physicochemical properties of CZA and $\mathrm{CZA}_{\text {citric }}$ metallic functions

\begin{tabular}{|c|c|c|c|c|c|c|c|c|}
\hline \multirow[t]{2}{*}{ Metallic function } & \multicolumn{3}{|c|}{ Composition (wt \%) } & \multirow[t]{2}{*}{$\operatorname{BET}\left(\mathrm{m}^{2} / \mathrm{g}_{\text {cat. }}\right)$} & \multirow[t]{2}{*}{$\mathrm{Cu}$ surface area $\left(\mathrm{m}^{2} / \mathrm{g}_{\mathrm{Cu}}\right)$} & \multirow[t]{2}{*}{$\mathrm{Cu}(\mathrm{nm})$} & \multirow[t]{2}{*}{$\mathrm{CuO}(\mathrm{nm})$} & \multirow[t]{2}{*}{$\mathrm{D}_{\mathrm{Cu}}(\%)$} \\
\hline & $\mathrm{CuO}$ & $\mathrm{ZnO}$ & $\mathrm{Al}_{2} \mathrm{O}_{3}$ & & & & & \\
\hline $\mathrm{CZA}$ & 64.3 & 22.5 & 9.7 & 64 & 28.7 & 12.0 & 9.2 & 4.39 \\
\hline $\mathrm{CZA}_{\text {citric }}$ & 68.1 & 23.2 & 9.4 & 20 & 12.4 & 29.5 & 20.5 & 2.02 \\
\hline
\end{tabular}

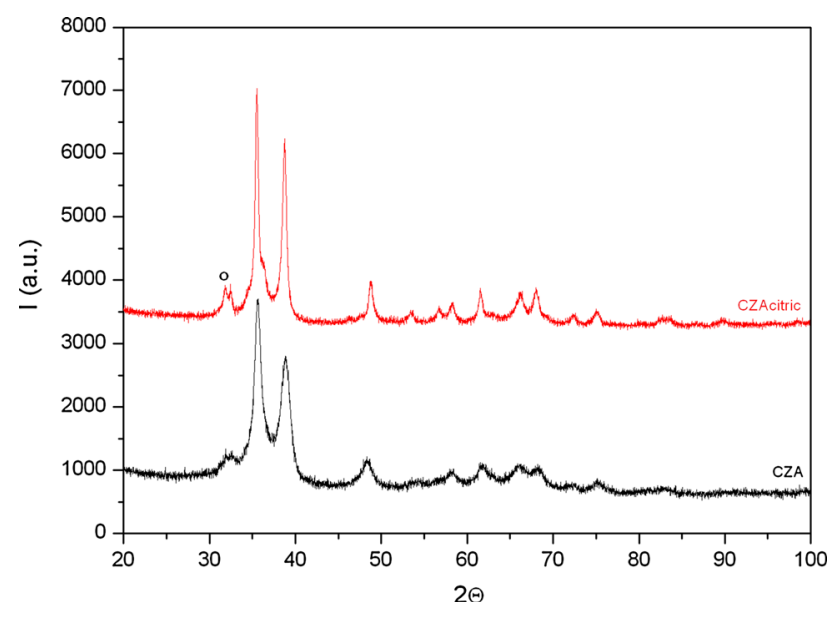

Fig. 1 XRD patterns for catalysts obtained by the carbonate (CZA) and citric method (CZAcitric): White circle- $\mathrm{ZnO}$, the rest of the reflexes- $\mathrm{CuO}$

patterns (Fig. 1) of the studied metallic catalysts, the diffraction lines characteristic for any of possible solid solutions and spinels are not observed. Additionally, the formation of $\mathrm{CuZn}$ solid solutions was ruled out since the reflections positions $(2 \Theta$ value) for the pure $\mathrm{CuO}$ and $\mathrm{ZnO}$, taken from the crystal structure crystalograpic data base [46], are the same as for the $\mathrm{CuO}$ and $\mathrm{ZnO}$ phase which are present in the studied catalysts (Fig. 1). In the case of CZA, the diffraction lines (mainly from $\mathrm{CuO}$ phase) are broader in comparison with the analogical diffraction lines for $\mathrm{CZA}_{\text {citric }}$. The differences in the XRD signal width are related to sizes of the crystallite, which are present in the catalysts after calcination. The metallic function obtained by the carbonate method consists of smaller $\mathrm{CuO}$ crystallites than metallic function obtained by the citric method. Calculation carried out according to the Rietveld refinement method (Table 1), confirmed that the CZA contains $\mathrm{CuO}$ crystallites of $9.2 \mathrm{~nm}$ whereas $\mathrm{CZA}_{\text {citric }}$ contains crystallites of $20.5 \mathrm{~nm}$.

The TPR profiles (Fig. 2) of CZA and $\mathrm{CZA}_{\text {citric }}$ exhibit one reduction peak related to $\mathrm{Cu}^{2+}$ to $\mathrm{Cu}^{0}$ reduction. No other reduction peaks are visible, which hints that there is only one type of $\mathrm{Cu}^{2+}$ species in all samples undergoing reduction. The metallic function obtained by the carbonate method is reduced at lower temperatures, just below the reduction of pure $\mathrm{CuO}\left(283{ }^{\circ} \mathrm{C}\right)$ while the metallic function obtained by the citric method is reduced at higher temperatures $\left(350{ }^{\circ} \mathrm{C}\right)$. In addition, the TPR peak for CZA is

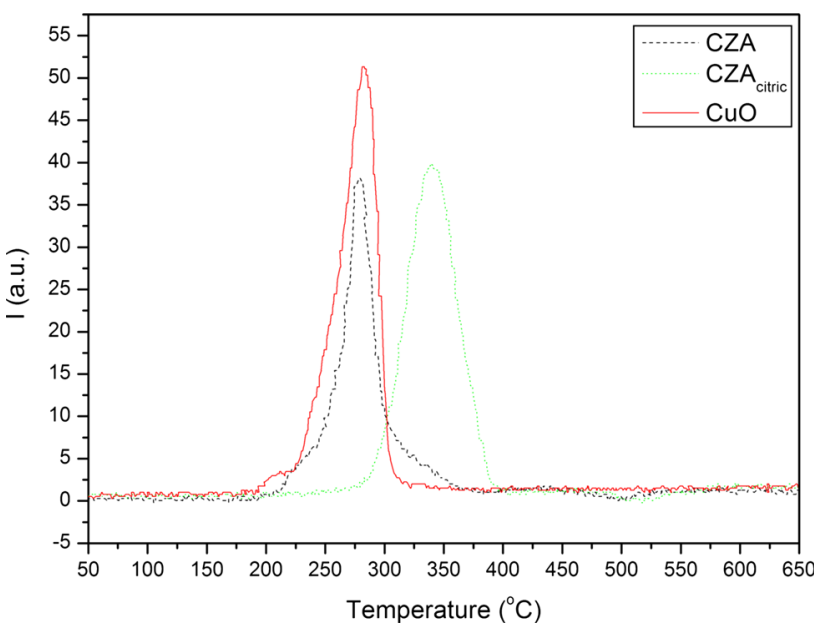

Fig. 2 TPR profiles of the metallic functions obtained by the carbonate (CZA) and citric method (CZAcitric)

narrower in comparison with the TPR peak recorded for $\mathrm{CZA}_{\text {citric. }}$. The differences in the reduction temperature and in the width of TPR peaks result from the differences in

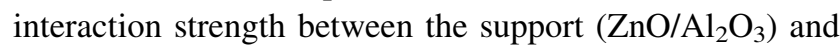
$\mathrm{CuO}$ which is the consequence of differences in coppers dispersion $\left(\mathrm{D}_{\mathrm{Cu}}\right)$ between CZA and $\mathrm{CZA}_{\text {citric }}$ (Table 1). As it can be seen, metallic function synthesized by carbonate method exhibits twice as high copper dispersion $\left(\mathrm{D}_{\mathrm{Cu}}=4.39 \%\right)$ as metallic function obtained by citric method $\left(\mathrm{D}_{\mathrm{Cu}}=2.02 \%\right)$. Highly dispersed $\mathrm{CuO}$ interacts stronger with the support what may lead to redaction temperature decrease. Smaller $\mathrm{CuO}$ crystallites, characteristic for CZA, are reduced faster and at lower temperature than $\mathrm{CuO}$ crystallites, which are present in $\mathrm{CZA}_{\text {citric}}$. Moreover, bigger $\mathrm{CuO}$ crystallites exhibit lower surface, which is available for the hydrogen during the reduction process. Thus the reduction of bigger $\mathrm{CuO}$ crystallites is hindered and it can be one of the reasons for the TPR peak widening [47]. These results are in good agreement with the reports already published $[48,49]$.

\subsection{Acidic Function Characterization (CZA/K10, CZA/ TPA-K10, $\mathrm{CZA}_{\text {citric }} / \mathrm{K} 10, \mathrm{CZA}_{\text {citric }} / \mathrm{TPA}-\mathrm{K} 10$ )}

In Fig. 3 the XRD patterns of the commercial montmorillonite K10, pure TPA and modified montmorillonite K10 


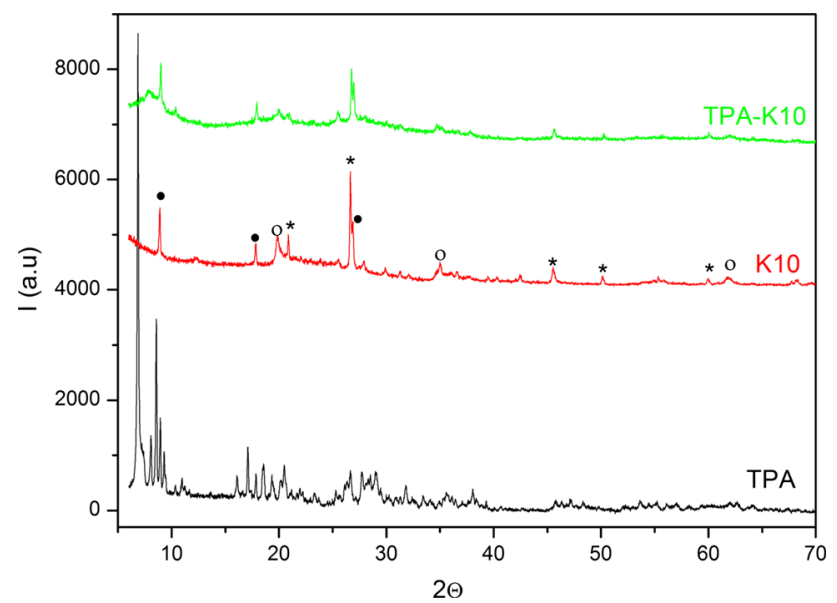

Fig. 3 XRD patterns: tungstophosphoric acid TPA, montmorillonite K10, modified montmorillonite TPA-K10: Black circle-muscovite, asterisk- $\mathrm{SiO} 2$, white circle-montmorillonite

(TPA-K10) are shown. In the case of K10, apart from diffraction peaks assigned to montmorillonite phase, the diffraction lines derived from muscovite and $\mathrm{SiO}_{2}$ are observed. The same diffraction lines but of lower intensity are present in the diffractograms of TPA-K10. The decrease in diffraction peaks intensities proves that the montmorillonite support looses part of its crystallinity after modification with TPA. The same phenomena was observed by Yadav et al. [50]. who supported dodecatungstophophoric acid on K10-montmorillonite. On the other hand, no diffraction lines from TPA are visible on the TPA-K10 XRD pattern. This lack of the reflexes points that TPA is well dispersed on the surface of montmorillonite K10.

The K10 modification with TPA changes the BET surface area of the support (Table 2) and the pore size distribution (Fig. 4). Before the modification, the BET surface area of montmorillonite $\mathrm{K} 10$ is $248 \mathrm{~m}^{2} / \mathrm{g}$ while after TPA deposition its surface decreases to $95 \mathrm{~m}^{2} / \mathrm{g}$. In both samples, the mesopores dominate with the maximum for the pores of $38 \AA$ A (Fig. 4). The drop in the BET surface area for TPA$\mathrm{K} 10$ in comparison with montmorillonite K10 is the result of the decrease in the amount of pores and their volume. It can be stated that the TPA deposition on the K10 surface leads to the blockage of the small pores and limits the availability of the pores with higher diameters. Nevertheless, the modification with TPA results in an increase of the micropore volume from $4 \cdot 10^{-3}$ to $2 \cdot 10^{-2} \mathrm{~cm}^{3} / \mathrm{g}$. Due to the TPA deposition, the micropores, which are accessible from the surface of montmorillonite K10, are blocked and the new micropores are formed simultaneously as a result of filling in the existing mesopores. This effect leads to the mesopore volume decrease.

In order to estimate the amount of TPA on the surface of $\mathrm{K} 10$, the UV-Vis analysis was performed. Based on these results, the experimental amount of deposited TPA was
Table 2 Characterization of montmorillonite K10 and modified montmorillonite TPA-K10

\begin{tabular}{lclll}
\hline $\begin{array}{l}\text { Acidic } \\
\text { function }\end{array}$ & $\begin{array}{l}\text { BET } \\
\left(\mathrm{m}^{2} / \mathrm{g}\right)\end{array}$ & $\begin{array}{l}\text { Pores size } \\
\mathrm{BJH}_{\text {des. }}(\mathrm{A})\end{array}$ & $\begin{array}{l}\text { Pores volume } \\
\mathrm{BJH}_{\text {des. }}\left(\mathrm{cm}^{3} / \mathrm{g}\right)\end{array}$ & $\begin{array}{l}\text { Micro pores } \\
\text { volume } \mathrm{V}_{\mathrm{t}} \\
\left(\mathrm{cm}^{3} / \mathrm{g}\right)\end{array}$ \\
\hline $\mathrm{K} 10$ & 248 & 38 & 0.36 & $4 \times 10^{-3}$ \\
TPA-K10 & 95 & 38 & 0.12 & $2 \times 10^{-2}$ \\
\hline
\end{tabular}

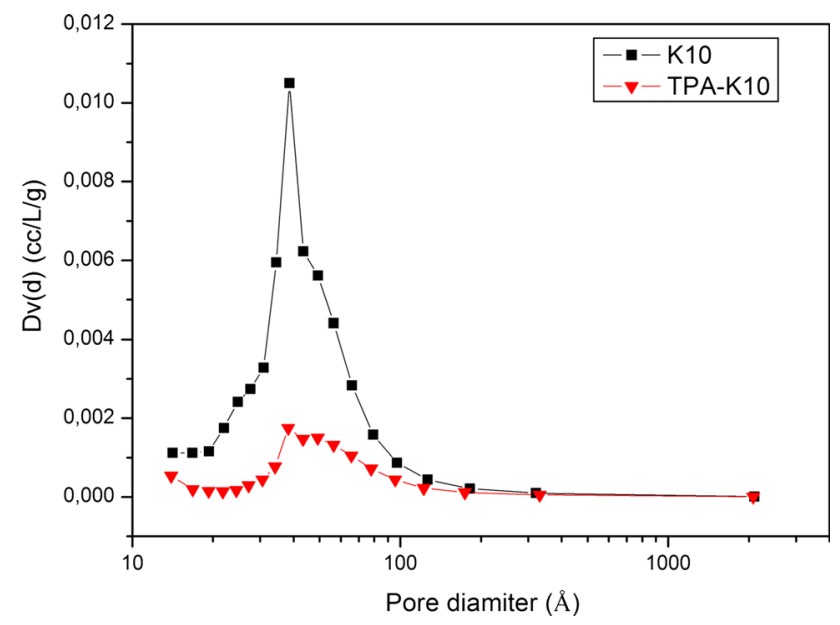

Fig. 4 Influence of the montmorillonite K10 modification with TPA on pore sizes distribution

determined. In Fig. 5 the UV-Vis absorption bands of pure TPA and TPA-K10 are given. For both pure TPA and TPAK10 two peaks at 222 and $265 \mathrm{~nm}$ are visible. The former one is due to the charge transfer from terminal oxygen to tungsten in $\mathrm{W}=\mathrm{O}$ and the latter one is assigned to the charge transfer from bridge oxygen to tungsten in W-O-W $[51,52]$. The presence of the same UV-Vis adsorption bands, in the case of pure TPA and TPA-K10, proves that TPA has been successfully deposited on the surface of K10. The quantitative experiments revealed that the total amount of TPA is sufficient to cover the surface of K10 only with 0.8 monolayer, meaning an uneven K10 surface coverage. This result was further confirmed by FTIR experiments.

The acidity of K10, TPA-K10 and pure TPA was evaluated based on FTIR measurements with pyridine (Py) adsorption as a probe molecule. Since the IR spectra of the adsorbed pyridine on the Brønsted and Lewis sites are different, it is possible to determine both the acidic strength and the concentration of these two types of acidic centers. The pyridine adsorbed on the Brønsted sites, is protonated $\left(\mathrm{PyH}^{+}\right)$while on the Lewis sites it is coordinatively bonded (PyL) with the aprotic sites. Besides, the presence of $\mathrm{H}$-bonded pyridine is observed $\left(\mathrm{Py}{ }^{\cdots} \mathrm{H}\right)$. 


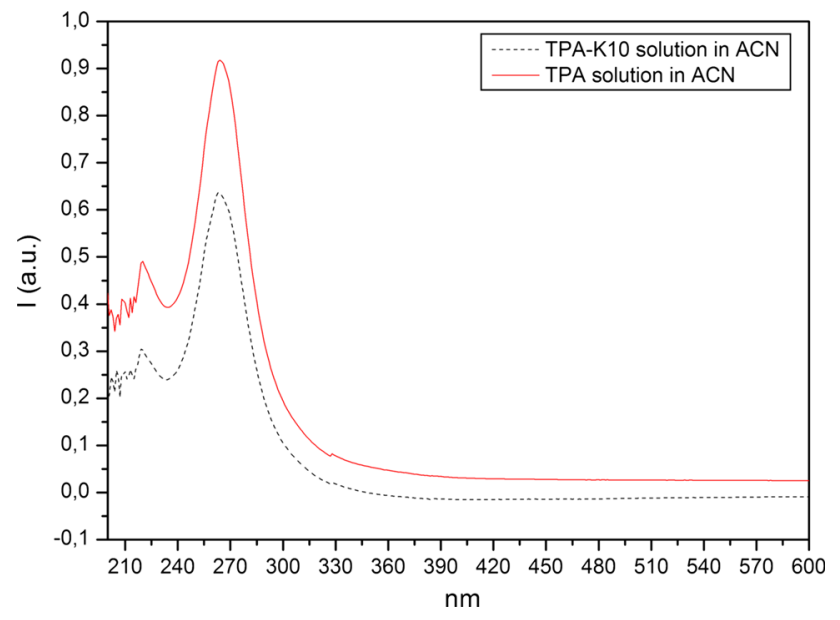

Fig. 5 UV-Vis analysis of pure TPA and modified montmorillonite K10 with TPA

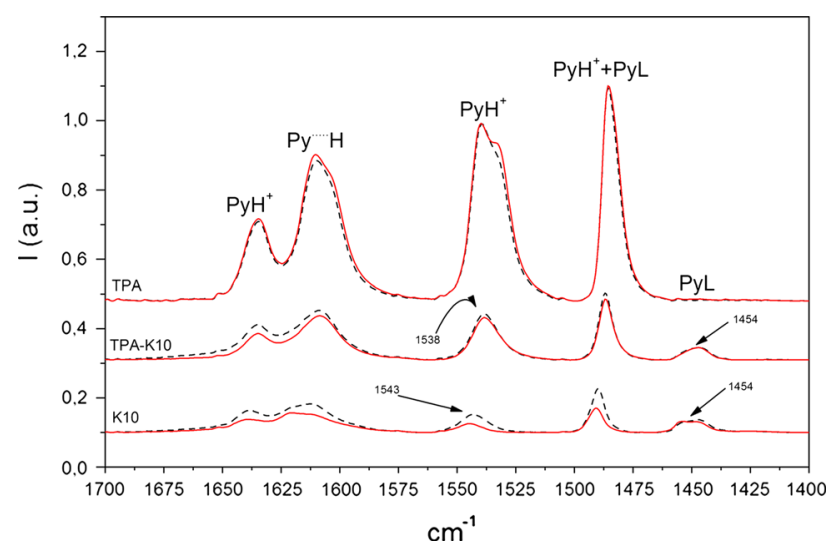

Fig. 6 FTIR pyridine adsorption on montmorillonite K10 (1), K10TPA (2) TPA (3); - pyridine desorption at $150 \mathrm{oC}$,-pyridine desorption at $350^{\circ} \mathrm{C}$. All samples activated at $250^{\circ} \mathrm{C}$

On the surface of K10 both the Brønsted and Lewis acidic sites are present (Fig. 6) and characterized by bands at 1,543 and $1,454 \mathrm{~cm}^{-1}$ respectively. On the other hand, TPA exhibits only acidity of Brønsted type and therefore there is no band in the range assigned to pyridine coordinately bonded with the aprotic sites for TPA. The modification of K10 with TPA leads to the increase in the intensity of the band at $1,543 \mathrm{~cm}^{-1}$ and its position shift toward lower wave numbers $\left(1,538 \mathrm{~cm}^{-1}\right)$. In the case of the TPA-K10 sample, the band assigned to pyridine adsorbed on the Brønsted acidic sites is observed at the same frequencies as for pure TPA i.e.: $1,538 \mathrm{~cm}^{-1}$. This band shifting shows that TPA is deposited on the montmorillonite K10 surface and interacts with the support. From the other hand, the band at $1,454 \mathrm{~cm}^{-1}$ stays unaltered after deposition of TPA on the surface of K10. From this, one can conclude that K10 surface is not completely covered with TPA, what support results obtained by UVVis measurements.
The increase in the intensity of the band assigned to pyridine adsorbed on Brønsted acidic sites of TPA-K10 in comparison with $\mathrm{K} 10$, proves that the acidity of TPA-K10 is higher than for the support. The increase in the acidity of TPA-K10 results from higher concentration of Brønsted acid sites and their higher strength as well (Table 3).

\subsection{Catalytic Activity}

\subsubsection{Methanol Dehydration}

The influence of TPA deposition on the K10 surface was investigated in methanol dehydration to DME under atmospheric pressure (Fig. 7). Apart from DME and water, no other products were found. Deposition of TPA on the surface of K10 improves methanol conversion to DME and acidic function activity. In the case of TPA-K10, methanol conversion reaches $95 \%$ at $210{ }^{\circ} \mathrm{C}$ whereas for $\mathrm{K} 10$ methanol conversion at $220{ }^{\circ} \mathrm{C}$ is $30 \%$ and it increases to $85 \%$ at $340{ }^{\circ} \mathrm{C}$. The changes in activity between $\mathrm{K} 10$ and TPA-K10 results from differences in acidity between K10 and TPA-K10. It has been proved by pyridine -FTIR studies that modified K10 exhibits higher density and strength of Brønsted acids site in comparison with pure K10.

\subsubsection{Direct DME Synthesis from Syngas}

The catalytic measurements show that unmodified and modified K10 with TPA can act as active components of hybrid catalysts for STD process. DME, methanol, $\mathrm{CO}_{2}$ and water were products of the reaction. The catalytic results for CZA/K10 and CZA/TPA-K10 are presented in the Fig. $8(\mathrm{a}, \mathrm{b})$ and for $\mathrm{CZA}_{\text {citric }} / \mathrm{K} 10$ and $\mathrm{CZA}_{\text {citric }} / \mathrm{TPA}-$ K10. in the Fig. 9 (a, b). For all hybrid catalysts, high $\mathrm{CO}_{2}$ selectivity, between 25 and $35 \%$, was found what shows that the water gas shift reaction plays an important role in the STD process. In case of $\mathrm{CZA} / \mathrm{K} 10$, high methanol yields are observed that can point that reaction is limited by dehydration step due to low acidity of K10 and high activity of metallic function. Taking into account the reaction scheme, removing the methanol from reaction system could shift an equilibrium toward DME formation and increase DME yields. In order to achieve this goal, K10 was substituted by more acidic TPA-K10 in hybrid catalyst. The obtained results show that methanol yield is lowered and DME yield is increased when CZA/TPA-K10 is used as a hybrid catalysts. In the same time, no other byproducts were detected. The difference in activities between CZA/K10 and CZA/TPA-K10 are the most pronounced at temperatures below $320{ }^{\circ} \mathrm{C}$. At $280{ }^{\circ} \mathrm{C}$ the DME yield is 20 and $42 \%$ respectively for CZA/K10 and CZA/TPA-K10. Additionally, substitution K10 with more 
Table 3 Concentration of acidic sites and their strength in TPA, K10 and TPA-K10. Activation temperature: $-250{ }^{\circ} \mathrm{C}^{\mathrm{a}},-350{ }^{\circ} \mathrm{C}^{\mathrm{b}}$

\begin{tabular}{|c|c|c|c|c|}
\hline Acidic component & $\mathrm{T}_{\text {des. }}\left({ }^{\circ} \mathrm{C}\right)$ & $\begin{array}{l}\mathrm{PyH}+(\mu \mathrm{mol} / \mathrm{g}) \\
1,545 \mathrm{~cm}^{-1}\end{array}$ & $\begin{array}{l}\text { Pyl }(\mu \mathrm{mol} / \mathrm{g}) \\
1,454 \mathrm{~cm}^{-1}\end{array}$ & $\begin{array}{l}\text { PyH+ } \\
\text { Acidic strength }\end{array}$ \\
\hline \multirow[t]{3}{*}{ K10 } & $150^{\mathrm{a}}$ & 177 & 49 & - \\
\hline & $350^{\mathrm{b}}$ & 59 & 49 & 0.33 \\
\hline & $150^{\mathrm{b}}$ & 118 & 57 & - \\
\hline \multirow[t]{3}{*}{ TPA-K10 } & $150^{\mathrm{a}}$ & 877 & 57 & - \\
\hline & $350^{\mathrm{b}}$ & 510 & 51 & 0.58 \\
\hline & $150^{\mathrm{b}}$ & 798 & 57 & - \\
\hline \multirow[t]{2}{*}{ TPA } & $150^{\mathrm{a}}$ & 3,317 & 0 & - \\
\hline & $150^{\mathrm{b}}$ & 3,480 & 0 & - \\
\hline
\end{tabular}

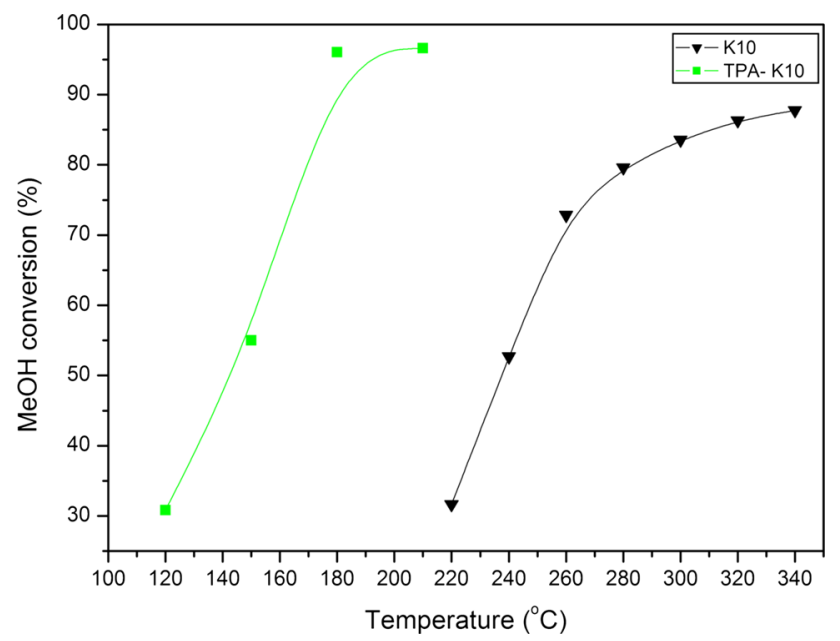

Fig. 7 Influence of acidic function modification on methanol dehydration to DME

acidic TPA-K10 enhances the CO conversion (Fig. 10) without increasing selectivity to $\mathrm{CO}_{2}$ or to any other byproducts. At higher temperatures, decrease in DME yield is observed for both hybrid catalysts. The observed decrease in DME yield results from decrease in CO conversion.. The similar trend for DME yield going through maximum was observed by Ereña et al. [53] Authors state that at low temperatures there is competitive adsorption between $\mathrm{CO}$ and $\mathrm{CO}_{2}$ on metallic function causing low $\mathrm{CO}$ conversion. On the other hand, decrease in conversion at higher temperature is due to theromodyhnamic limitation and $\mathrm{Cu}$ sintering $[54,55]$.

The FTIR-pyridine adsorption studies revealed (Table 3) that modified K10 with TPA exhibits higher concentration of Brønsted acid sites and higher strength of Brønsted acid sites in comparison with unmodified K10. On the other hand, both K10 and TPA-K10 possesses the same Lewis acidity. Thus, one can conclude that only Brønsted acid sites contribute in the methanol dehydration step to DME and increase in their strength and concentration is responsible for higher CZA/TPA-K10 activity.
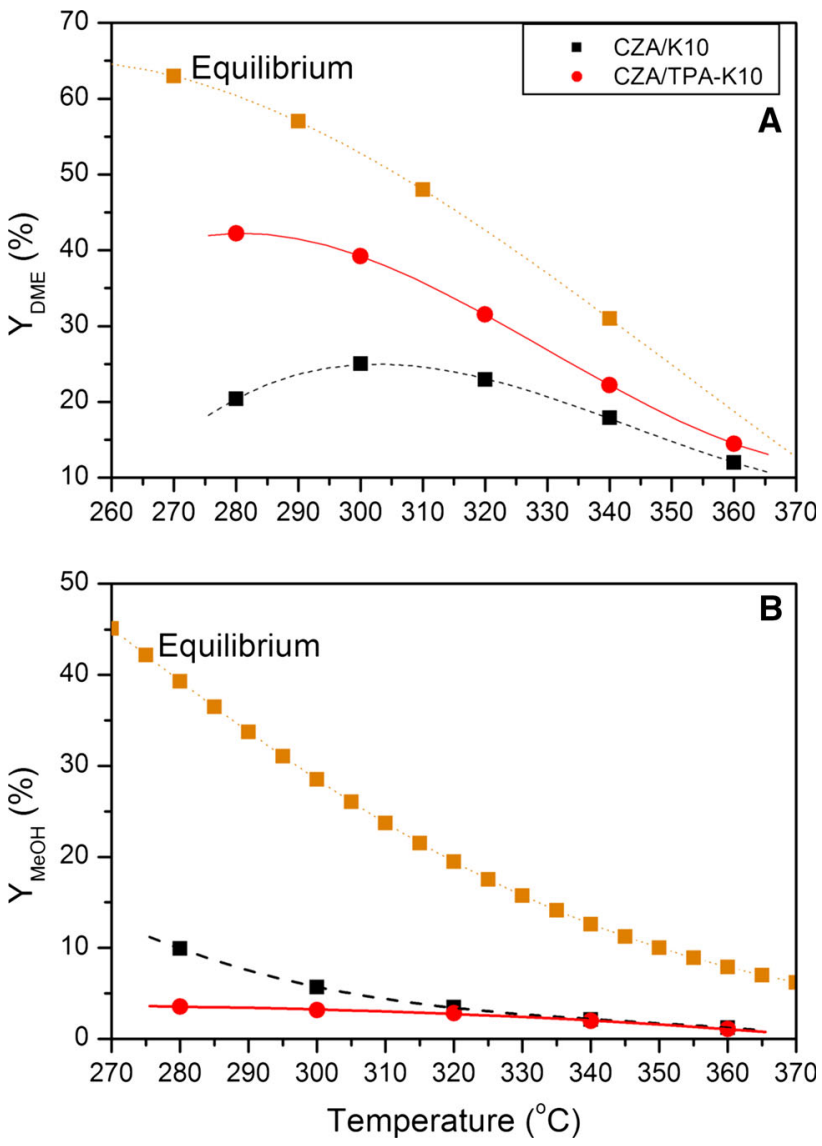

Fig. 8 DME yield (a) and methanol yield (b) for CZA/K10 and CZA/TPA-K10; ...... equilibrium. For methanol yields, dotted line corresponds to the limit values of methanol yield calculated based on thermodynamic equilibrium of methanol formation at 40 bar using eq. published by Graaf et al.32

These results are in agreement with the results presented by Ramos et al. [31]. who showed linear correlation between Brønsted acid site concentrations and activity of various acid functions in methanol dehydration to DME. On the other hand, the lack of light paraffins in the products of the STD process proves that the surface acidity of TPA-K10 is too low for the methanol dehydration to hydrocarbons. 

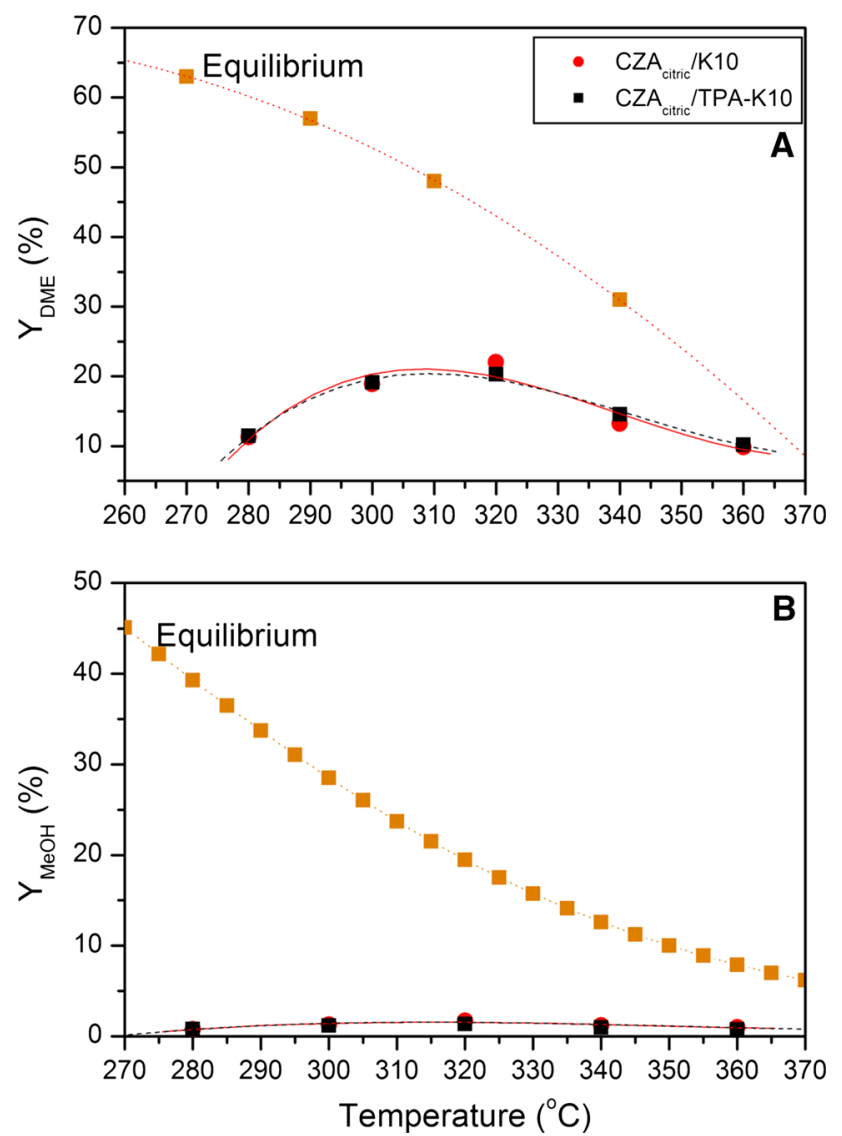

Fig. 9 DME yield (a) and methanol yield (b) for CZAcitric/K10 and CZAcitric/TPA-K10; ... $\mathbf{\square} .$. equilibrium. For methanol yields, dotted line corresponds to the limit values of methanol yield calculated based on thermodynamic equilibrium of methanol formation at 40 bar using eq. published by Graaf et al.32

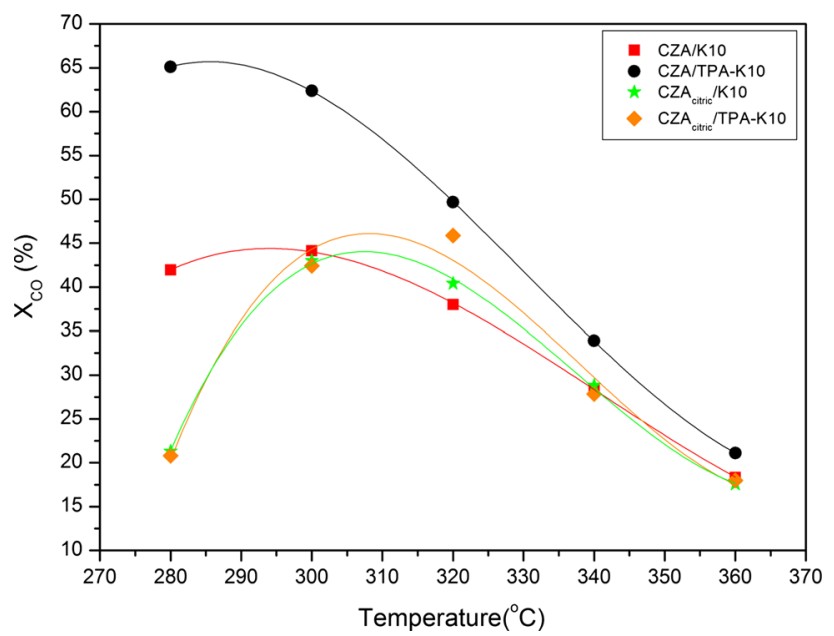

Fig. $10 \mathrm{CO}$ conversion (XCO) for CZA/K10, CZA/TPA-K10, CZAcitric/K10, CZAcitric/TPA-K10

In spite of the differences in the acidity between montmorillonite K10 and TPA-K10, K10 substitution with TPA-K10 in the hybrid catalysts containing $\mathrm{CZA}_{\text {citric }}$ as metallic function has almost no effect on the activity. The yield to methanol (Fig. 9B) and DME (Fig. 9A) in entire temperature range are the same for both hybrid catalyst $\mathrm{CZA}_{\text {citric }} / \mathrm{K} 10$ and $\mathrm{CZA}_{\text {citric }} / \mathrm{TPA}-\mathrm{K} 10$. Moreover, only slight changes in $\mathrm{CO}$ conversion are observed between these two metallic functions (Fig. 10). When $\mathrm{CZA}_{\text {citric }}$, which possesses low copper surface area $\left(12.4 \mathrm{~m}^{2} / \mathrm{g}_{\mathrm{Cu}}\right)$ and low copper dispersion $\left(\mathrm{D}_{\mathrm{Cu}}=2.02 \%\right)$, is employed as metallic function, STD process is limited by the methanol synthesis rate due to low activity of $\mathrm{CZA}_{\text {citric. }}$ In this case, methanol which is formed on redox center can be already efficiently dehydrated to DME when K10 is used as acidic function. Therefore, further increase in Brønsted acidity of acidic component, by TPA deposition on surface of K10, has no influence on the final activity of hybrid catalyst. Since, in this case the activity of $\mathrm{CZA}_{\text {citric }}$ is low and activity of K10 is high,the only way to increase the yield to DME is to substitute $\mathrm{CZA}_{\text {citric }}$ with the metallic function of higher activity. It can be seen that DME yield for CZA/K10 (Fig. 8A) is higher than for $\mathrm{CZA}_{\text {citric }} / \mathrm{K} 10$ (Fig. 9A) in entire temperature range. The differences between yields for $\mathrm{CZA} / \mathrm{K} 10$ and $\mathrm{CZA}_{\text {citric }} / \mathrm{K} 10$ are less pronounced when they approach equilibrium DME yield at higher temperatures.

The full set of selectivity to methanol, DME and $\mathrm{CO}_{2}$ for investigated catalysts is presented in supplementary information (SI).

\section{Conclusions}

The application of the carbonate and citric method results in metallic functions of different properties, allowing to perform syngas-to-DME process under methanol synthesis regime or methanol dehydration regime. The acidic properties of K10 can be tuned by TPA deposition on its surface, solely leading to enhancement of Brønsted acidity of K10 while Lewis acidity is unchanged. Both unmodified K10 and modified K10 with TPA can be successfully used as active components of hybrid catalysts in STD process. The influence of acidity strengthening on DME yield depends whether the reaction is limited by methanol synthesis rate or methanol dehydration rate. When syngas-toDME process is perform under methanol synthesis regime, the Brønsted acidity enhancement of K10 by TPA deposition has no impact on DME yield increase and the only way to improve DME yield is to use metallic function of higher activity. On the other hand when syngas-to-DME process is carried out under methanol dehydration regime then the use of TPA-K10 was found to improve DME yield significantly. It has been proved that Brønsted acid site are the active centers for DME dehydration when K10 and TPA-K10 are considered. Based on performed studies one 
can conclude that activity of metallic function and acidic function should be optimized and matched completely, if highly active hybrid catalysts for STD process are required. The optimization should be performed for the function on which the reaction rate is the limiting step of the overall rate of STD.

Acknowledgments The financial support of National Science Centre Poland (Grant project nr. N N204 279937) is gratefully acknowledged.

Open Access This article is distributed under the terms of the Creative Commons Attribution License which permits any use, distribution, and reproduction in any medium, provided the original author(s) and the source are credited.

\section{References}

1. Arcoumanis C, Bae C, Crookes R, Kinoshita E (2008) Fuel 87:1014-1030

2. Semelsberger TA, Borup RL, Greene HL (2006) J Power Sources 156:497-511

3. Yoo J, Choi H, Chunga C, Choa SM (2006) J Power Sources 163:103-106

4. Serov A, Kwak C (2009) Appl Catal B 91:1-10

5. Kaeding WW, Butter SA (1980) J Catal 61:155-164

6. Cai G, Liu Z, Shi R, He C, Yang L, Sun C, Chang Y (1995) Appl Catal A 125:29-38

7. Li JL, Zhang XG, Inui T (1996) Appl Catal A 147:23-33

8. Bonuraa G, Arenaa F, Mezzatestab G, Cannillaa C, Spadaro L, Frusteri F (2011) Catal Today 171:251-256

9. Flores JH, Solórzano G, da Silva M (2008) Appl Surf Sci 254:6461-6466

10. Khoshbin R, Haghighi M (2013) Chem Eng Res Des 91:1111-1122

11. Qi GX, Zheng XM, Fei JH, Hou ZY (2001) J. of Molec. Catal. A: Chemical 176:195-203

12. Venugopala A, Palgunadib J, Deogb J, Joob O, Shin C (2009) J. of Molec. Catal. A: Chemical 302:20-27

13. Fujita T, Nakamura J (1998) Catal Lett 56:119-124

14. Chen HB, Liao DW, Yu LJ, Lin YJ, Yi J, Zhang HB, Tsai KR (1999) Appl Surf Sci 147:85-93

15. Günter M, Ressler T, Bems B, Büscher C, Genger T, Hinrichsen O, Muhler M, Schlögl R (2001) Catal Lett 71:37-44

16. Bae J, Potdar HS, Kang S, Jun K (2008) Energy Fuels 22:223-230

17. Erena J, Garona R, Arandes JM, Aguayo AT, Bilbao J (2005) Catal Today 107:467-473

18. Xia J, Mao D, Zhang B, Chen Q, Tang Y (2004) Catal Lett 98:235-240

19. Fei J, Hou Z, Zhu B, Lou H, Zheng X (2006) Appl Catal A 304:49-54

20. Takegchi T, Yanagisawa K, Inui T, Inoue M (2000) Appl Catal A 192:201-209

21. Vishwanathan V, Jun KW, Kim JW, Roh HS (2004) App. Catal. A 276:251-255

22. Jiang S, Hwang JS, Jin T, Cai T, Cho W, Baek YS, Park SE (2004) Bull Korean Chem Soc 25:185-191
23. Hassanpour S, Yaripour F, Taghizadeh M (2010) Fuel Process Technol 91:1212-1221

24. Hendriksen BA, Pearce DR, Rudham R (1972) J Catal 24:82-87

25. Shen WJ, Jun KW, Choi HS, Lee KW (2000) Bull Korean Chem Soc 17:210-216

26. Yoo KS, Kim JH, Park MJ, Kim SJ, Joo OS, Jung KD (2007) Appl Catal A 330:57-62

27. Xia J, Mao D, Tao W, Chen Q, Zhang Y, Tang Y (2006) Micropor. Mesopor. Mater. 91:33-39

28. Kim JH, Park MJ, Kim SJ, Joo OS, Jung KD (2004) Appl Catal A 264:37-41

29. Xu M, Lunsford JH, Goodman DW, Bhattacharyya A (1997) Appl Catal A 149:289-301

30. Joo OS, Jung KD, Han SH (2002) Bull Korean Chem Soc 23:1103-1110

31. Ramos FS, Duarte AM, Borges L, Monteiro JL, Fraga MA, Sousa-Aguiar EF (2005) Catal Today 101:39-44

32. Skrzypek J, Słoczyński J, Ledakowicz S Methanol Synthesis, Polish Scientific Publishers 1994, ISBN 83-01-11490-8

33. Soriente A, Arienzo R, De Rosa M, Palombi L, Spinella A, Scettri A (1999) Green Chem 1(3):157-162

34. Singh DU, Singh PR, Samant SD (2004) Tetrahedron Lett 45:4805-4807

35. Guerreiro ED, Gorriz OF, Rivarole JB, Arrúa LA (1997) Appl Catal A 165:259-271

36. Bartley GJ, Burch R, Chappell RJ (1988) Appl. Catal. 43:91-104

37. Datka J, Gil B (2007) Microporous Mesoporous Mater 103:225-229

38. Žilková N, Bejblová M, Gil B, Zones S, Burton A, Chen C, Musilová Z, Košová G, Cějka J (2009) J Catal 266:79-91

39. Datka J, Gil B, Kubacka A (1997) Zeolitem 18:245-248

40. Ertl G, Knözinger H, Shüth F, Weitkamp J (2008) Handbook of heterogenous catalysis. Wiley-VCH, Weinheim

41. Giamello E, Fubin B, Lauro P (1985) Appl. Catal 94:120-128

42. Trifo F, Vaccari A, Busetto C, Piero GD, Manara G (1984) J Catal 85:260-266

43. Garbassi F, Petrin G (1984) J Catal 90:106-112

44. Moretti G, Fibro G, Lo M, Porta J, Porta P (1989) Surf Interface Anal 14:325-336

45. Behrens M, Zander S, Kurr P, Jacobsen N, Senker J, Koch G, Ressler T, Fischer R.W., Shlögl R (2013) J.Am. Chem. Soc. 135(16):6061-6068

46. http://www.icdd.com/products/pdf4.htm, ref. code 04-012-7238, ref code 04-006-7189

47. Słoczyński J, Grabowski R, Kozłowska A, Olszewski PK, Stoch J (2003) Phys Chem Chem Phys 5:4631-4640

48. Aguila G, Guerrero S, Araya P (2013) Appl Catal A 463:56-63

49. Chang F, Kuo W, Lee K (2003) Appl Catal A 246:253-264

50. Yadav GD, Kirthivasan N (1997) Appl Catal A 154:29-53

51. Ding Y, Gaoa Q, Zhang G, Li H, Wang J, Yan L, Suo J (2004) J. of Molec. Catal. A: Chemical 218:161-170

52. Kala Raj NK, Puranik VG, Gopinathan C, Ramaswamya AV (2003) Appl Catal A 256:265-273

53. Ereña J, Garoña R, Arandes JM, Aguayo AT, Bilbao J (2005) Catal Today 107-108:467-473

54. Sun JT, Metcalfe IS, Sahibzada M (1999) Ind Eng Chem Res 38:3868-3872

55. Bartholomew CH (2001) Appl. Catal. 212:17-60 